\title{
Correction to: Effect of gervital in attenuating hepatotoxicity caused by methotrexate or azathioprine in adult albino rats
}

\author{
Manal Abdul-Hamid ${ }^{1}$ (D) Eman Salah Abdel-Reheim ${ }^{2} \cdot$ Walaa Hegazy $^{3} \cdot$ Ahmed Allam $^{4} \cdot$ Sarah I. Othman ${ }^{5}$. \\ Maha Abdulla Alwaele ${ }^{5}$ Samraa Hussein Abdel-Kawi ${ }^{6}$
}

Published online: 24 February 2022

○) Springer-Verlag GmbH Germany, part of Springer Nature 2022

\section{Correction to: Environmental Science and Pollution Research https://doi.org/10.1007/s11356-022-18903-x}

The correct grant number in the Funding should be RGP-1441-0002.

The Original article has been corrected.

Publisher's note Springer Nature remains neutral with regard to jurisdictional claims in published maps and institutional affiliations.

The original article can be found online at https://doi.org/10.1007/ s11356-022-18903-x

Manal Abdul-Hamid

medo_bio@yahoo.com;

manal.mohamed3@science.bsu.edu.eg

1 Histology and Cell Biology Division, Zoology Department, Faculty of Science, Beni-Suef University, Beni Suef, Egypt

2 Molecular Physiology Division, Zoology Department, Faculty of Science, Beni-Suef University, Beni Suef, Egypt

3 Basic Science Department, Faculty of Physical Therapy, Nahda University, Beni Suef, Egypt

4 Developmental Biology Division, Zoology Department, Faculty of Science, Beni-Suef University, Beni Suef, Egypt

5 Biology Department, Faculty of Science, Princess Nourah Bint Abdulrahman University, Riyadh, Saudi Arabia

6 Medical Histology \& Cell Biology Department, Faculty of Medicine, Beni-Suef University, Beni Suef, Egypt 